\title{
Organization Identifier Primary Indicator
}

National Cancer Institute

\section{Source}

National Cancer Institute. Organization Identifier Primary Indicator. NCI Thesaurus. Code C93872.

Specifies whether this is the main or principal organization identifier. 